\title{
GAD65 Promoter Polymorphism rs2236418 Modulates Harm Avoidance in Women via Inhibition/Excitation Balance in the Rostral ACC
}

\author{
Lejla Colic, ${ }^{1,2}$ Meng Li, ${ }^{1,3}$ Liliana Ramona Demenescu, ${ }^{1}$ Shija Li, ${ }^{4}$ OIris Müller, ${ }^{5}$ Anni Richter, ${ }^{2}$ Gusalija Behnisch, ${ }^{2}$ \\ Constanze I. Seidenbecher, ${ }^{2,6}$ Oliver Speck, 2,6,7,8 @Björn H. Schott, $2,6,9$ @Oliver Stork, ${ }^{5,6}$ and Martin Walter ${ }^{1,2,3,6,10,11}$ \\ ${ }^{1}$ CANLAB, 39120 Magdeburg, Germany, ${ }^{2}$ Leibniz Institute for Neurobiology, 39118 Magdeburg, Germany, ${ }^{3}$ Department of Psychiatry and Psychotherapy, \\ Otto von Guericke University of Magdeburg, 39120 Magdeburg, Germany, ${ }^{4}$ Key Laboratory of Brain Functional Genomics (MOE\&STCSM), Shanghai \\ Changning-ECNU Mental Health Center, School of Psychology and Cognitive Science, East China Normal University, Shanghai, China, ${ }^{5}$ Department of \\ Genetics and Molecular Neurobiology, Institute of Biology, Otto von Guericke University of Magdeburg, 39120 Magdeburg, Germany, ${ }^{6}$ Center for Behavioral \\ Brain Sciences, 39106 Magdeburg, Germany, ${ }^{7}$ Department of Biomedical Magnetic Resonance, Otto von Guericke University, 39120 Magdeburg, Germany, \\ ${ }^{8}$ German Centre for Neurodegenerative Diseases, 39120 Magdeburg, Germany, ${ }^{9}$ Department of Psychiatry and Psychotherapy, Charité Universitätsmedizin \\ Berlin, 10117 Berlin, Germany, ${ }^{10}$ Department of Psychiatry and Psychotherapy, University of Tübingen, 72076 Tübingen, Germany, and ${ }^{11}$ Max Planck \\ Institute for Biological Cybernetics Tübingen, 72076 Tübingen Germany
}

Anxiety disorders are common and debilitating conditions with higher prevalence in women. However, factors that predispose women to anxiety phenotypes are not clarified. Here we investigated potential contribution of the single nucleotide polymorphism rs2236418 in GAD2 gene to changes in regional inhibition/excitation balance, anxiety-like traits, and related neural activity in both sexes. One hundred and five healthy individuals were examined with high-field (7T) multimodal magnetic resonance imaging (MRI); including resting-state functional MRI in combination with assessment of GABA and glutamate (Glu) levels via MR spectroscopy. Regional GABA/Glu levels in anterior cingulate cortex (ACC) subregions were assessed as mediators of gene-personality interaction for the trait harm avoidance and moderation by sex was tested. In AA homozygotes, with putatively lower GAD2 promoter activity, we observed increased intrinsic neuronal activity and higher inhibition/excitation balance in pregenual ACC (pgACC) compared with G carriers. The pgACC drove a significant interaction of genotype, region, and sex, where inhibition/excitation balance was significantly reduced only in female AA carriers. This finding was specific for rs2236418 as other investigated single nucleotide polymorphisms of the GABA synthesis related enzymes (GAD1, GAD2, and GLS) were not significant. Furthermore, only in women there was a negative association of pgACC GABA/Glu ratios with harm avoidance. A moderated-mediation model revealed that pgACC GABA/Glu also mediated the association between the genotype variant and level of harm avoidance, dependent on sex. Our data thus provide new insights into the neurochemical mechanisms that control emotional endophenotypes in humans and constitute predisposing factors for the development of anxiety disorders in women.

Key words: anxiety endophenotypes; fMRI; GABA/glutamate; harm avoidance; sex differences

Significance Statement

Anxiety disorders are among the most common and burdensome psychiatric disorders, with higher prevalence rates in women. The causal mechanisms are, however, poorly understood. In this study we propose a neurobiological basis that could help to explain female bias of anxiety endophenotypes. Using magnetic resonance brain imaging and personality questionnaires we show an interaction of the genetic variation rs2236418 in the GAD2 gene and sex on GABA/glutamate (Glu) balance in the pregenual anterior cingulate cortex (pgACC), a region previously connected to affect regulation and anxiety disorders. The GAD2 gene polymorphism further influenced baseline neuronal activity in the pgACC. Importantly, GABA/Glu was shown to mediate the relationship between the genetic variant and harm avoidance, however, only in women. 


\section{Introduction}

Anxiety endophenotypes are considered as critical parameters for the disposition of psychopathologies including anxiety disorders (Mathews and Macleod, 2005). Epidemiological data report female bias in anxiety disorders (McLean et al., 2011; Donner and Lowry, 2013). Clarifying the neurobiological mechanisms underlying these endophenotypes and their sex specificity is crucial for the development of new treatments.

Investigations of neurobiological mechanisms of anxiety have highlighted the role of corticolimbic circuits encompassing anterior cingulate cortex (ACC), ventromedial prefrontal cortex, and amygdala (Dörfel et al., 2014) in anxiety development.

The ACC is characterized by a marked rostrocaudal division (Bush et al., 2000) reflected in the receptor distribution (PalomeroGallagher et al., 2009) and metabolite composition (Dou et al., 2013). The anterior midcingulate cortex (aMCC) is connected to salience detection and cognition networks (Menon and Uddin, 2010), whereas the pregenual ACC (pgACC) shows strong connections to the affective network (Yu et al., 2011) and is implicated in downregulation of amygdala activity, modulating the processing of emotions and the formation of fear memory (Etkin et al., 2011; Giustino and Maren, 2015).

At neurotransmitter levels, emotion regulation through the pgACC depends on the balance of GABA and glutamate (Glu), which control neural excitability, plasticity and network stability (Cline, 2005). In general, prominent GABAergic system involvement in emotion regulation and anxiety disorders has been shown in preclinical and clinical studies (Nuss, 2015; Goddard, 2016). In the pgACC, which shows an adaptive response to anticipatory anxiety (Straube et al., 2009), dysregulation of inhibition/ excitation balance has been reported for clinical populations (Phan et al., 2005; Long et al., 2013). Further evidence for a role of GABA in general affect regulation comes from a combined functional magnetic resonance imaging (fMRI)-MR spectroscopy (MRS) study that revealed a correlation between pgACC deactivation during emotion processing and local GABA concentrations (Northoff et al., 2007).

GABA is synthetized by two isoforms of glutamic acid decarboxylase (GAD65, encoded by GAD2; GAD67, encoded by GAD1 gene), which differ in expression and activitydependent regulation (Esclapez et al., 1994). GAD65 regulates phasic GABA release and couples to neuronal activity, whereas GAD67 is connected to cytoplasmic GABA production and metabolic activity (Soghomonian and Martin, 1998; Patel et al., 2006). GABA synthesis is subject to sex differences, mod-

Received July 13, 2017; revised March 14, 2018; accepted March 19, 2018.

Author contributions: C.I.S., O. Speck, B.H.S., O. Stork, and M.W. designed research; L.C., S.L., I.M, A.R., and G.B. performed research; L.C., M.L., and L.R.D. analyzed data; L.C., M.L., L.R.D., S.L., I.M., A.R., C.I.S., O. Speck, B.H.S., 0 . Stork, and M.W. wrote the paper.

This work was supported by the German Research Foundation (SFB779/B05 to 0. Stork, SFB779/B14 to C.IS., SFB 779/A08 to B.H.S.,SFB779/A06 and DFG Wa2673/4-1 to M.W.), the Center for Behavioral Brain Sciences (CBBS NN05 to M.W.) and Leibniz Association (Pakt für Forschung und Innovation to M.W.); and L.C. and A.R. were postdoctoral fellows of the SFB779; and I.M. was member of the Leibniz PostdocNetwork. We thank Renate Blobel-Lüer and Dr. Claus Tempelmann (Department of Neurology, Otto von Guericke University of Magdeburg) for MR data acquisition, Dr. Jörn Kaufmann (Department of Neurology, Otto von Guericke University of Magdeburg) for technical support on MRS data analysis and Dr. Anton Lord for biostatistical advice.

Conflict of interest: M.W. is member of advisory boards and/or gave presentations for the following companies: Boehringer, Bayer, and Heel. M.W. has further conducted a clinical trial (IIT) with financial support from Janssen Research \& Development, LLC unrelated to this study. The remaining authors declare no competing financial interests.

Correspondence should be addressed to Dr. Martin Walter, CANLAB, ZENIT Building 65, Leipziger Str. 44, 39120 Magdeburg, Germany. E-mail: martin.walter@med.ovgu.de.

DOI:10.1523/JNEUROSCI.1985-17.2018

Copyright $\odot 2018$ the authors $\quad 0270-6474 / 18 / 385068-11 \$ 15.00 / 0$ ulated by gonadal hormones (Davis et al., 1999; Seney et al., 2013). The GAD2 promoter region has been identified as a target for estrogen receptors (Hudgens et al., 2009), and estrogens modulate both GAD65 and GAD67 mRNA levels (McCarthy et al., 1995; Ikeda et al., 2015).

We therefore hypothesized genetic effects, via GABA synthesis, on the inhibition/excitation balance in the pgACC that would mediate its role in anxiety. To address this question, an $A>G$ single-nucleotide polymorphism (SNP) in the promoter region of GAD2 (chromosome 10p, position - 243, rs2236418) was chosen, which has been previously associated with a sixfold increase in GAD65 transcription levels in vitro (Boutin et al., 2003). To validate the specificity of GAD2 rs2236418 we tested additional candidate SNPs in the GABAergic pathway: in the GAD2 gene (position 26211729 in the intron region, rs10508715 A>G; Unschuld et al., 2009), in the sister gene GAD1 (chromosome 2, position 170851590 in the intron region, rs3791850 C>T; Hettema et al., 2006; and position 170836945 in the intron region, rs769390, A $>$ C; Marenco et al., 2010) as well as in the glutaminase gene (GLS chromosome 2, position 190964627, rs13035504 A $>$ G; Yin et al., 2016).

The effects of polymorphism on the inhibition/excitation balance were studied with high-field (7T) multivoxel ${ }^{1} \mathrm{H}$ MRS via GABA/Glu ratio, and on the brain activity using resting-state (rs)-fMRI, measuring amplitudes of low-frequency fluctuations (ALFF) and regional homogeneity (ReHo). To test for the behavioral implications of the observed variations we determined individual proneness to anxiety as indicated by the harm avoidance scale of the Temperament and Character Inventory (TCI; Cloninger et al., 1994). The expected sex specificity was determined for all investigated measures and their interactions.

\section{Materials and Methods}

Study design

The study sample consisted of 105 healthy subjects (age $=27.09 \pm 6.72$, 44 females) pooled from three studies. Measurements included: genotyping, rs-fMRI, and ${ }^{1} \mathrm{H}$ MRS at ultra-high-field strength 7T. All three studies used identical protocols for recruitment and measurements: the scan order of the MRS voxels and rs-fMRI was the same. Some subjects were used as controls for patient studies, thus after the resting-state scan, they performed additional fMRI tasks which differed according to the respective patient study, but this fMRI task did not affect prior MRS or restingstate measurements. All subjects were in good physical condition and medication free as determined by relevant medical history. Subjects were asked about previous hospitalization (including psychotherapy), medical conditions, and medication. Medication for neurological diseases (i.e., epilepsy), diabetes and hypo/hyperthyroidism were considered as exclusion criteria. Medical history was acquired and approved by a study physician. Psychiatric disorders according to DSM-IV and ICD-10 were excluded using the German version 5.0.0 of the M.I.N.I. Mini International Neuropsychiatric Interview (Sheehan et al., 1998). Further exclusion criteria were left-handedness as assessed with the short form (10 items) of the Edinburgh Handedness Inventory (Oldfield, 1971) and MRI contraindications, such as metallic implants or tinnitus. All three studies were approved by the Institutional Review Board of the University of Magdeburg, and all subjects provided written informed consent in accordance with the Declaration of Helsinki.

\section{Genotyping}

Whole-blood samples were collected from participants in EDTA-coated tubes (BD Vacutainer, K3E, 7.2 mg, BD Biosciences, 368884) and stored at $4^{\circ} \mathrm{C}$. Genomic DNA was extracted from blood leukocytes using the GeneMole automated system (Mole Genetics AS) according to the manufacturer's protocol. Genotyping was performed using PCR followed by allele-specific restriction analysis. Briefly, the DNA fragment on chromosome $10 \mathrm{p} 12$ containing the GAD2 $-243 \mathrm{~A}>\mathrm{G}$ polymorphism (NCBI 


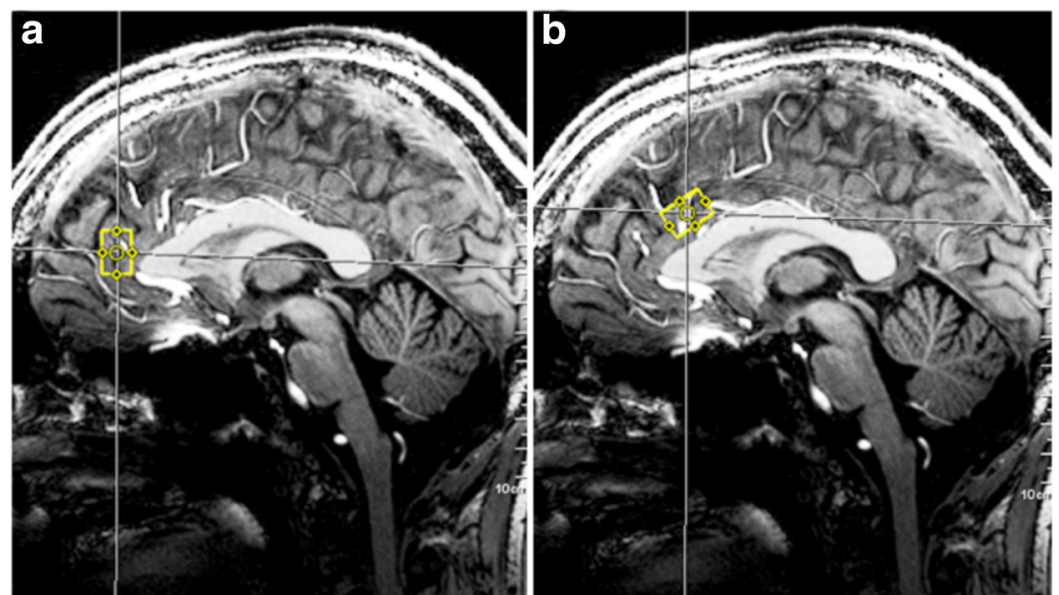

Figure 1. MRS voxel. Position of the 7T MRS voxel (yellow box) in the $\operatorname{pgACC}(\boldsymbol{a})$ and the aMCC $(\boldsymbol{b})$ for a single subject.

$r s$-fMRI. Subjects were instructed to lay still and awake with their eyes closed during the scanning session. Whole-brain $\mathrm{T} 2{ }^{*}$-weighted echoplanar images (EPIs) were acquired $(280$ time points, 62 axial slices, $\mathrm{TE}=22 \mathrm{~ms}$, TR $=$ $2800 \mathrm{~ms}$, flip angle $=80^{\circ}$, bandwidth $=2246$ $\mathrm{Hz}$, isotropic voxel size $=2 \mathrm{~mm}$ ). Sequence parameters were optimized to circumvent intravoxel dephasing and loss of signal, particularly in lower mPFC. Online motion and distortion correction were applied (Speck et al., 2008). The first 10 EPIs were discarded to allow for steady-state magnetization, and EPIs were visually inspected for data quality and scanning artifacts. Preprocessing was performed using Statistical Parametric Mapping (SPM12; Wellcome Trust Centre for Neuroimaging) and DPARSFA toolbox v2.1 (Chao-Gan and YuFeng, 2010). EPIs were first temporally corrected for acquisition delay (slice timing), followed by a spatial correction for head motion (realignment). Subjects with head motion

accession number: rs2236418) was amplified using the primers GAD2-F: 5'-CGA AAG ACC AAA AGC CAG AG-3' and GAD2-B: 5' -TTC TAC CAA GGC GCT GAA AT- $3^{\prime}$ and standard Taq polymerase (Qiagen). The resulting PCR products were digested with DraI (ThermoFisher Scientific, FD0224), yielding two fragments $(279+575 \mathrm{bp})$ for the A allele or a single fragment ( $854 \mathrm{bp}$ ) for the G allele. DNA fragments were separated on a $1 \%$ agarose gel stained with Midori Green (Biozym Scientific) and visualized under UV light.

To control for specificity of effects related to the rs 2236418 variant, we further performed genotyping for GAD2 rs10508715 (Unschuld et al., 2009) as well as for rs3791850 (Hettema et al., 2006) and rs769390 (Marenco et al., 2010) in the GAD1 gene and for glutaminase (GLS) rs13035504 (Yin et al., 2016). Details of additional genotyping protocols are available from the authors upon request.

\section{Personality assessment}

To assess self-reported harm avoidance, we used the corresponding scale from the TCI (Cloninger et al., 1994). The TCI was designed as a tool to dissociate and predict clinical phenotypes and was built as a psychobiological model of personality based on temperaments, heritable and stable dimensions of "involuntary emotional processes" and characters, dimensions developed later in life of "voluntary rational processes". Temperament harm avoidance was connected to cognitive anxiety symptoms (Cloninger, 1987). It is composed of four subscales, which cover different aspects of anxiety propensity: anticipatory worry, fear of uncertainty, shyness with strangers, and fatigability and asthenia (weakness). Harm avoidance is strongly positively correlated with neuroticism and negatively with extraversion domains from the NEO Personality Inventory and Eysenck personality dimensions (Stallings et al., 1996; De Fruyt et al., 2000), thus describing an anxiety-like trait. Moreover, the questionnaire and scales (in the German version) display high internal consistency and factor structure (Richter et al., 2000) as well as long-term (Josefsson et al., 2013) and cross-cultural stability (Miettunen et al., 2006), highlighting its transferability when exploring the underlying biological and environmental determinants of differences in heathy populations. From the entire sample, 72 subjects filled out the questionnaire. Internal consistency of harm avoidance was good (for 69 subjects item by item scores available; Cronbach's $\alpha=0.9, N=35$ items).

\section{MRI data acquisition and analysis}

MR images were acquired on a 7T scanner with a 32-channel head array coil (Siemens Healthineers). After automated shimming, we first acquired a high-resolution T1-weighted anatomical MR image, using a magnetization-prepared rapid gradient echo (MPRAGE) sequence $\left(\mathrm{TE}=2.73 \mathrm{~ms}, \mathrm{TR}=2300 \mathrm{~ms}\right.$, TI $=1050 \mathrm{~ms}$, flip angle $=5^{\circ}$, band width $=150 \mathrm{~Hz} /$ pixel, isotropic voxel size $=0.8 \mathrm{~mm}$ ). The individual anatomical images were segmented and used for coregistration of the rs-fMRI data or to calculate partial volumes of the MRS voxels. exceeding $2 \mathrm{~mm}$ were excluded from further analysis. The MPRAGE image was coregistered to the individual mean EPI image from realignment to improve the following spatial normalization into the MNI stereotactic reference frame (Montreal Neurological Institute). Normalized EPIs were smoothed using a double voxel length Gaussian kernel of $4 \mathrm{~mm}$ full-width at half-maximum (FWHM). Smoothing kernel size was optimized for strong local activations within the boundaries of cytoarchitectonic subregions, leading to a smaller than usual kernel size.

After the regression of mean white matter signal, mean CSF signal and six motion parameters (obtained from the realignment of the nonmotion-corrected data), ALFFs (Zuo et al., 2010) was calculated in the frequency band of $0.01-0.1 \mathrm{~Hz}$. For the calculation of ReHo (Zang et al., $2004)$, smoothing was omitted, and temporal filtering $(0.01-0.1 \mathrm{~Hz})$ and "scrubbing" via cubic spline interpolation were applied. Scrubbing was done for the time points which exceeded a framewise displacement threshold of 0.5 as calculated with the method described by Jenkinson et al. (2002), as well as for adjacent time points. Subjects who had $>13$ volumes $(5 \%)$ with $>0.5$ FD were excluded from further analysis. The similarity of time series was estimated for 19 neighboring voxels in the calculation for ReHo. To test for between-group differences, ALFFs and ReHo were converted to $z$ maps using Fisher's $r$-to- $z$ transformation (Chao-Gan and Yu-Feng, 2010). ReHo $z$ maps were additionally smoothed with $4 \mathrm{~mm}$ kernel.

MRS. After region-specific automated shimming, a stimulated-echo acquisition mode sequence was used, and ${ }^{1} \mathrm{H}$ spectra were acquired from the pgACC $\left(\right.$ voxel size $\left.=20 \times 15 \times 10 \mathrm{~mm}^{3}\right)$ and aMCC $($ voxel size $=$ $25 \times 15 \times 10 \mathrm{~mm}^{3} ; 128$ averages, $\mathrm{TE}=20 \mathrm{~ms}, \mathrm{TR}=3000 \mathrm{~ms}, \mathrm{TM}=10$ $\mathrm{ms}$, bandwidth $=2800 \mathrm{~Hz}$; Fig. 1). Water signal with instance single average served as internal reference for quantification and eddy current correction. Spectral data $(0.6-4.0 \mathrm{ppm})$ were analyzed with the LCModel v6.3.0 (Stephen Provencher, Oakville, ON, Canada; Provencher, 2001). Absolute concentrations of target metabolites (GABA and Glu) with respective Cramér-Rao Lower Bound (CRLB) and FWHM values for spectral line-width estimation were obtained. Exclusion criteria for unreliable quantification were as follows: CRLB $>20 \%$, FWHM $>24 \mathrm{~Hz}$, SNR $<20$. Metabolite concentrations were expressed in institutional units (i.u.), due to the absence of individual correction for T1 and T2 relaxation differences between in vitro and in vivo metabolites. For each MRS voxel, the GABA/Glu ratio was calculated as an approximation of the inhibition/excitation balance. Metabolite ratios were residualized for individual gray matter partial volume of the respective voxel, as calculated from the segmented anatomical images using voxel-based morphometry with VBM8 (Structural Brain Mapping Group, University of Jena, Germany), implemented in the SPM8 (Wellcome Trust Centre for Neuroimaging). 
Table 1. Study sample characteristics with respect to GAD2 rs2236418

\begin{tabular}{|c|c|c|c|}
\hline Variable & $A A$ & G carriers & Statistical test \\
\hline Whole sample & 65 subjects & 40 subjects & $\chi_{(1)}^{2}=3.208, p=0.073^{*}$ \\
\hline Age & $27.58 \pm 7.25$ & $26.28 \pm 5.73$ & $U=1102, p=0.189$ \\
\hline Sex & 28 females & 16 females & Pearson $\chi_{(1)}^{2}=0.096, p=0.756$ \\
\hline $\mathrm{BMI}^{a}$ & $\begin{array}{l}23.49 \pm 2.88 \\
(n=59)\end{array}$ & $\begin{array}{l}24.46 \pm 3.20 \\
(n=36)\end{array}$ & $U=887, p=0.179$ \\
\hline Smoking status ${ }^{a}$ & $\begin{array}{l}21 \text { yes } \\
(n=62)\end{array}$ & $\begin{array}{l}10 \text { yes } \\
(n=38)\end{array}$ & Pearson $\chi_{(1)}^{2}=0.629, p=0.428$ \\
\hline Alcohol consumption ${ }^{a, b}$ & $\begin{array}{l}39 \text { yes } \\
(n=56)\end{array}$ & $\begin{array}{l}20 \text { yes } \\
(n=33)\end{array}$ & Pearson $\chi_{(1)}^{2}=0.759, p=0.384$ \\
\hline Contraceptive use $^{a}$ & $\begin{array}{l}13 \text { yes } \\
(n=27)\end{array}$ & $\begin{array}{l}9 \text { yes } \\
(n=16)\end{array}$ & Pearson $\chi_{(1)}^{2}=0.264, p=0.607$ \\
\hline GAD2 rs10508715 & $58 \mathrm{AA}$ & $6 \mathrm{AA}$ & Pearson $\chi_{(1)}^{2}=59.404, p<0.001$ \\
\hline GAD1 rs3791850 & $37 C C$ & $20 C C$ & Pearson $\chi_{(1)}^{2}=0.359, p=0.549$ \\
\hline GAD1 rs769390 & $35 \mathrm{AA}$ & $17 \mathrm{AA}$ & Pearson $\chi_{(1)}^{2}=0.945, p=0.331$ \\
\hline GLS rs13035504 & $48 \mathrm{AA}$ & $33 \mathrm{AA}$ & Pearson $\chi_{(1)}^{2}=0.580, p=0.446$ \\
\hline
\end{tabular}

Mann-Whitney test was conducted to test for difference in age and BMI (mean \pm SD), and $\chi^{2}$ test of independence to test for distribution of genotype by sex, smoking status, alcohol consumption, or contraception use. All values were $p>$ 0.05 , two-sided. Allele frequencies of the whole dataset $(N=105)$ were within the Hardy-Weinberg equilibrium.

${ }^{a}$ The data were not available for all subjects; total number is written in brackets for the respective genotype group.

${ }^{b}$ Yes $=$ at least one drink per week-daily; $n_{0}=$ rarely-never.

${ }^{*} 0.1>p>0.05$

Table 2. Analyses sample characteristics with respect to GAD2 rs2236418

\begin{tabular}{|c|c|c|c|c|c|c|}
\hline Analysis & Groups & Subjects, $n$ & Age, mean $\pm S D$ & Mann-Whitney test & Sex, $n$ & $\chi^{2}$, interaction genotype $\times$ sex \\
\hline \multirow[t]{2}{*}{ Local intrinsic activity } & $\mathrm{AA}$ & 46 & $28.07 \pm 7.53$ & \multirow[t]{2}{*}{$U=474, p=0.035^{*}$} & 22 females & \multirow[t]{2}{*}{ Pearson $\chi_{(1)}^{2}=0.001, p=0.970$} \\
\hline & G carriers & 29 & $24.86 \pm 3.92$ & & 14 females & \\
\hline \multirow[t]{2}{*}{ Inhibition/excitation balance } & $\mathrm{AA}$ & 45 & $27.87 \pm 7.59$ & \multirow[t]{2}{*}{$U=403, p=0.136$} & 17 females & \multirow[t]{2}{*}{ Pearson $\chi_{(1)}^{2}=3.267, p=0.071^{\#}$} \\
\hline & G carriers & 23 & $25.30 \pm 4.48$ & & 6 females & \\
\hline \multirow[t]{2}{*}{ Behavioral correlates } & Males & 35 & $26.91 \pm 6.44$ & \multirow[t]{2}{*}{$U=441, p=0.653$} & & \\
\hline & Females & 27 & $26.63 \pm 6.69$ & & & \\
\hline \multirow{2}{*}{$\begin{array}{l}\text { Mediation model } 6 \text { (M }=p g A C C \text { GABA/Glu } \\
\text { and ALFF/ReHo beta estimate) }\end{array}$} & $\mathrm{AA}$ & 20 & $29.20 \pm 9.29$ & \multirow[t]{2}{*}{$U=140, p=0.066^{\#}$} & 12 females & \multirow[t]{2}{*}{ Pearson $\chi_{(1)}^{2}=0.631, p=0.427$} \\
\hline & G carriers & 21 & $24.52 \pm 4.09$ & & 10 females & \\
\hline \multirow[t]{2}{*}{ Mediation model 59 ( $\mathrm{M}=\mathrm{ALFF} / \mathrm{ReH}$ o beta estimates) } & $\mathrm{AA}$ & 26 & $28.62 \pm 8.29$ & \multirow[t]{2}{*}{$U=190.5, p=0.047^{*}$} & 15 females & \multirow[t]{2}{*}{ Pearson $\chi_{(1)}^{2}=0.284, p=0.594$} \\
\hline & G carriers & 22 & $24.77 \pm 4.16$ & & 11 females & \\
\hline \multirow[t]{2}{*}{ Mediation model 59 (M = pgACC GABA/Glu) } & $\mathrm{AA}$ & 36 & $27.89 \pm 7.45$ & \multirow[t]{2}{*}{$U=347, p=0.083^{\#}$} & 16 females & \multirow[t]{2}{*}{ Pearson $\chi_{(1)}^{2}=0.028, p=0.867$} \\
\hline & G carriers & 26 & $25.27 \pm 4.61$ & & 11 females & \\
\hline
\end{tabular}

For each analysis number of subjects differed; indicated are genotype groups with age (mean \pm SD) and sex frequencies. Mann-Whitney test was conducted to test for difference in age, and $\chi^{2}$ test of independence to test for distribution of genotype by sex. Statistical threshold is $p<0.05$, two-sided.

${ }^{*} p<0.05 ;{ }^{*} 0.1>p>0.05$

Table 3. Study sample characteristics for additional polymorphisms

\begin{tabular}{|c|c|c|c|c|c|}
\hline Polymorphism & Groups & Age, mean $\pm S D$ & Mann-Whitney test & Sex, $n$ & $\chi^{2}$, interaction genotype $\times$ sex \\
\hline \multirow[t]{2}{*}{ GAD2 rs2236418 } & $A A$ & $27.58 \pm 7.25$ & \multirow[t]{2}{*}{$U=1102, p=0.19$} & 28 females & \multirow{2}{*}{ Pearson $\chi_{(1)}^{2}=0.1, p=0.76$} \\
\hline & G Carriers & $26.28 \pm 5.73$ & & 16 females & \\
\hline \multirow[t]{2}{*}{ GAD2 rs10508715 } & $\mathrm{AA}$ & $27.36 \pm 7.02$ & \multirow[t]{2}{*}{$U=1073, p=0.43$} & 22 females & \multirow[t]{2}{*}{ Pearson $\chi_{(1)}^{2}=2.80, p=0.094^{\#}$} \\
\hline & G Carriers & $26.65 \pm 6.31$ & & 19 females & \\
\hline \multirow[t]{2}{*}{ GAD1 rs3791850 } & $\mathrm{CC}$ & $27.09 \pm 6.17$ & \multirow[t]{2}{*}{$U=1162, p=0.53$} & 21 females & \multirow[t]{2}{*}{ Pearson $\chi_{(1)}^{2}=1.21, p=0.27$} \\
\hline & T Carriers & $27.14 \pm 7.48$ & & 21 females & \\
\hline \multirow[t]{2}{*}{ GAD1 rs769390 } & $\mathrm{AA}$ & $27.19 \pm 6.91$ & \multirow[t]{2}{*}{$U=1250, p=0.74$} & 25 females & \multirow[t]{2}{*}{ Pearson $\chi_{(1)}^{2}=2.09, p=0.15$} \\
\hline & C Carriers & $26.92 \pm 6.60$ & & 17 females & \\
\hline \multirow[t]{2}{*}{ GLS rs13035504 } & $\mathrm{AA}$ & $27.11 \pm 6.53$ & \multirow[t]{2}{*}{$U=795, p=0.44$} & 32 females & \multirow[t]{2}{*}{ Pearson $\chi_{(1)}^{2}=0.25, p=0.62$} \\
\hline & G Carriers & $26.41 \pm 6.80$ & & 10 females & \\
\hline
\end{tabular}

Mann-Whitney test was conducted to test for difference in age (mean \pm SD), and $\chi^{2}$ test of independence to test for distribution of genotype by sex. All values were $p>0.05$, two-sided.

" $0.1>p>0.05$.

Statistical analyses

To control for possible confounds, full set genotype groups for GAD2 rs2236418 were tested for age, sex, BMI, smoking, alcohol consumption, or contraception use. All variables were checked for normality with Kolmogorov-Smirnov test $(p<0.05)$, and subsequently Mann-Whitney's $U$ tests or $\chi^{2}$ tests were conducted (Table 1). Datasets for respective analyses varied due to scanner artifacts or excessive head movement during scanning (27 subjects excluded), insufficient MRS quality $($ aMCC $=28 ;$ pgACC $=14 ;$ both $=37$ subjects excluded $)$, or incomplete questionnaires (33 subjects excluded). Therefore, each analysis was done with the maximum number of participants available for the modality or combination of them and as a nuisance variable, age was checked again for possible difference between the groups (Table 2).

First, to determine the effects of genotype and sex on the local intrinsic neuronal activity we analyzed ALFF and ReHo $z$ maps within the boundaries of the ACC subregions. ACC search volume was created following a previously established protocol (Li et al., 2017), using a 50\% threshold for overlap of individual voxels. A two-way ANOVA was performed in 
SPM12 with genotype and sex as independent between-subject factors (46 AA, 22 females; 29 G carriers, 14 females). Because of a significant between-group difference in age (Table 2), it was included as nuisance covariate (Biswal et al., 2010). Statistical significance was set at $p<0.05$, peak-level familywise error (FWE)-corrected, for the search volume.

The second ANOVA model was set up to assess region-specific (pgACC vs aMCC) effects of GAD2 rs2236418 genotype, sex, and their interaction on the GABA/Glu ratio (45 AA, 22 females; 21 G carriers, 6 females). First, to determine GAD2 rs2236418 specificity, additional SNPs (GAD2: rs10508715; GAD1: rs3791850 and rs769390; and GLS: rs13035504) were tested with the same model (Bonferroni-corrected $p<$ 0.05 , equal to statistical threshold of $p<0.01$ ). For significant interactions post hoc Student's $t$ tests or Mann-Whitney $U$ tests were conducted. Second, to confirm metabolic specificity of the significant interaction on the ratio, we also compared GABA/Cr and Glu/Cr ratios, on an exploratory level $(p<0.05)$. The ANOVAs were computed using SPSS (IBM SPSS Statistics for Windows, v24.0) and included region as withinsubject factor, and genotype and sex as between-subject factors. Age was included as a covariate.

To test for potential behavioral relevance of the inhibition/excitation balance in the pgACC with respect to anxiety-related traits, a nonparametric partial correlation of GABA/Glu ratio and harm avoidance scores was computed, controlled for age. Taking sex effects into consideration, this correlation was computed separately for males and females (35 males, 27 females), with $p<0.025$, two-tailed, Bonferroni-corrected. Correlation coefficients were then compared for a significant difference with Fischer's $Z$ test with statistical threshold set at $Z>1.96$ (equivalent to $p<0.05$, two-sided), using VassarStats (website for statistical computation, Poughkeepsie, NY). To assess direct influence of sex on harm avoidance and/or pgACC GABA/Glu ratio post hoc Mann-Whitney $U$ tests were calculated afterward.

Last, to elucidate potential effects of the pgACC GABA/Glu ratio or baseline neuronal activity on the genotype-related prediction of harm avoidance, we performed mediation analyses using the SPSS extension PROCESS v2.15 (Preacher and Hayes, 2004). Mediation models are used to explain the indirect underlying influence of the predictor on the dependent variable through its interaction with a third-mediator variable. We included genotype GAD2 rs2236418 as predictor, harm avoidance as outcome and age as nuisance covariate. First, we calculated models that took into account two mediator variables (GABA/Glu pgACC with ALFF or ReHo $\beta$ estimate), as well as their additive effect ( $n=41$; Model 6 in PROCESS). Next, we estimated each mediator variable in a separate model ( $n=48$ for ALFF and ReHo; $n=62$ for GABA/Glu pgACC). We furthermore added sex as a moderating factor to account for any sex-specific effects (Model 59 in PROCESS). For all models, heteroscedasticityconsistent SEs were set and 95\% confidence intervals (CIs) were estimated via bootstrap resampling with 1000 repetitions.

\section{Results}

\section{Sample characteristics}

For the GAD2 rs2236418 subjects were grouped into AA homozygotes $(n=65,28$ females, age $=27.58 \pm 7.25)$ and $\mathrm{G}$ allele carriers (G carriers; $n=40,16$ females, age $=26.28 \pm 5.73 ; 31 \mathrm{AG}$ and 9 GG). There were no differences in all demographic factors between the groups (Table 1). Further analysis-specific differences of subgroups can be found in the Table 2. There were overall no differences between genotype groups for other SNPs as well (Table 3).

\section{Genotype differences in the local neuronal activity}

To determine the effects of genotype and sex on the intrinsic activity within ACC subregions, we computed ALFF and ReHo $z$ maps. Within the search area, there was an effect of genotype on both metrics with peak activation localized in the pgACC (Fig. 2). Compared with AA homozygotes, G carriers exhibited a trend toward decrease in intrinsic neuronal activity as indicated by ALFF values $\left([-442-2], t_{(70)}=3.67, p=0.059\right.$, FWE peak-level corrected; Fig. 2a) and significant lower ReHo at the same location $\left([-242-2], t_{(70)}=3.80, p=0.026\right.$, FWE peak-level corrected; Fig. $2 b)$. No significant genotype by sex interactions were found for either metric. However, a main effect of sex was present for ALFF in the pgACC $\left([638-2], t_{(70)}=4.62, p=0.004\right.$, FWE peak-level corrected), as well as marginally for ReHo in the aMCC $\left(\left[\begin{array}{lll}-6 & 24 & 24\end{array}\right], t_{(70)}=3.43, p=0.069\right.$, FWE peak-level corrected), with lower activation found in women.

\section{GAD2 rs2236418 and sex interaction on the GABA/Glu ratio in the pgACC}

To test for potential effects of the GAD2 rs2236418 polymorphism and sex on the regional inhibition/excitation balance in the pgACC and the aMCC, we analyzed the GABA/Glu ratio from ${ }^{1} \mathrm{H}$ MRS as dependent variable in an ANOVA model. We observed a Bonferroni-corrected significant two-way interaction of region and rs2236418 genotype for GABA/Glu ratios $\left(F_{(1,63)}=\right.$ 7.53, $p=0.008, \eta^{2}=0.11$ ) and a three-way interaction (region by genotype by sex; $F_{(1,63)}=8.66, p=0.005, \eta^{2}=0.12$; Fig. 3; Table 4). These effects were specific for the GAD2 rs2236418 as other SNPs did not show any significant interaction (Table 4). Post hoc $t$ tests revealed that female $\mathrm{G}$ carriers had significantly higher GABA/Glu ratios in the $\operatorname{pgACC}\left(t_{(36)}=-2.19, p=0.035\right.$; Fig. 3; Table 5).

Furthermore, in a follow-up exploratory analysis, for GAD2 rs2236418, region by genotype by sex interaction was identified for $\operatorname{GABA} / \mathrm{Cr}\left(F_{(1,63)}=4.92, p=0.03, \eta^{2}=0.072\right)$, and a trend level for region by genotype $\left(F_{(1,63)}=3.57, p=0.063, \eta^{2}=\right.$ 0.054 ), which was not the case for Glu/Cr ratio (Table 6), suggesting GABA levels as the driving force for the observed effect. From other tested SNPs, GLS rs13035504 showed significant region by genotype by sex interaction for $\mathrm{Glu} / \mathrm{Cr}\left(F_{(1,68)}=4.18, p=0.016\right.$, $\left.\eta^{2}=0.082\right)$ and trend-level for GABA/Cr $\left(F_{(1,62)}=3.56, p=\right.$ 0.064, $\eta^{2}=0.054$; Table 6).

\section{Harm avoidance correlates with GABA/Glu ratio in women}

To assess the functional relevance of the pgACC inhibition/excitation balance for anxiety-related traits, we computed nonparametric partial correlations of pgACC GABA/Glu ratios and harm avoidance, separately in male and female participants. A significant negative relationship between the pgACC GABA/Glu ratio and harm avoidance was observed in women $\left(\rho_{(24)}=-0.549\right.$, $p=0.004,95 \% \mathrm{CI}=[-0.768,-0.214])$, but not in men $\left(\rho_{(32)}=\right.$ $0.048, p=0.79,95 \% \mathrm{CI}=[-0.289,0.375])$. Fischer's $Z$ test confirmed a significant difference between the slopes $(Z=2.46$, equivalent to $p=0.014$; Fig. 4$)$. Women showed higher harm avoidance scores $(U=327.5, p=0.039)$, although there was no difference between the sexes for the pgACC GABA/Glu ratio $(U=450, p=0.75)$.

\section{Mediation model}

To clarify the relationship between GAD65 rs2236418 genotype, pgACC GABA/Glu ratio, baseline neuronal activity and harm avoidance, we performed mediation and moderated mediation analyses with genotype as predictor, harm avoidance as outcome, pgACC GABA/Glu or ALFF/ReHo as mediator variables, and sex as moderator variable.

The analyses revealed a significant effect only for the fully moderated model with the pgACC GABA/Glu as a mediator variable (index $=-3.147$, bootstrapped 95\% CI $=[-9.929$, $-0.478])$. Specifically, a genotype-dependent influence of the pgACC GABA/Glu ratio on harm avoidance was observable in women $(b=-3.088$, boot $95 \% \mathrm{CI}=[-9.896,-0.502])$, but not 

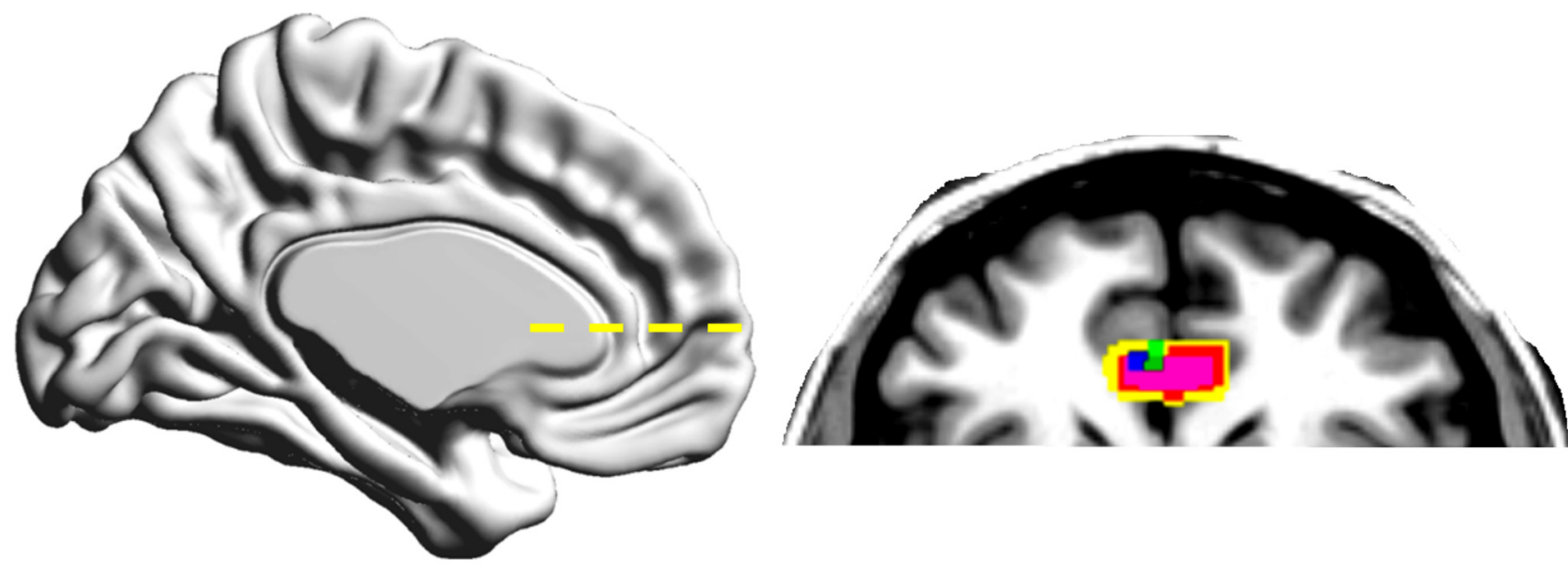

a

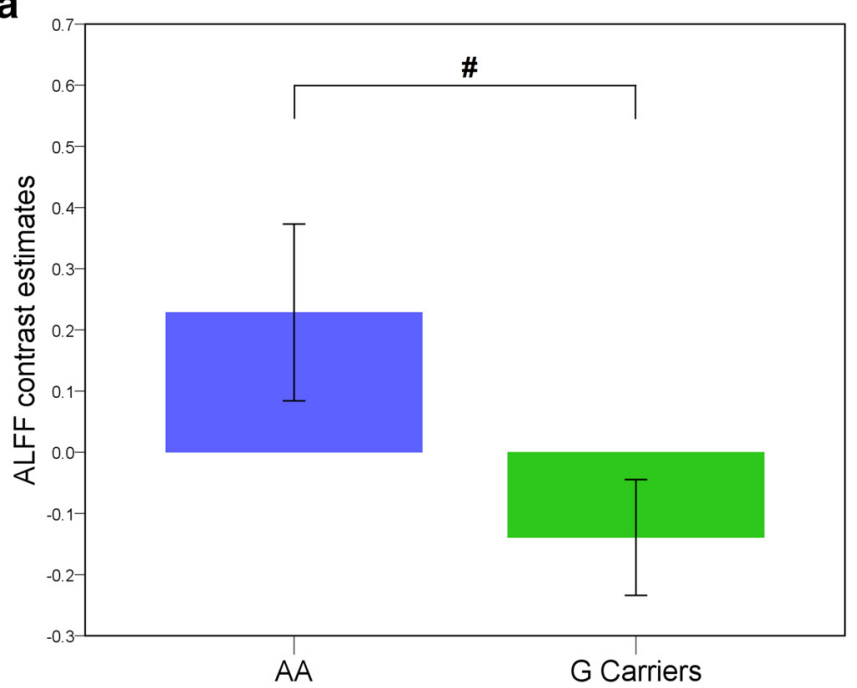

b

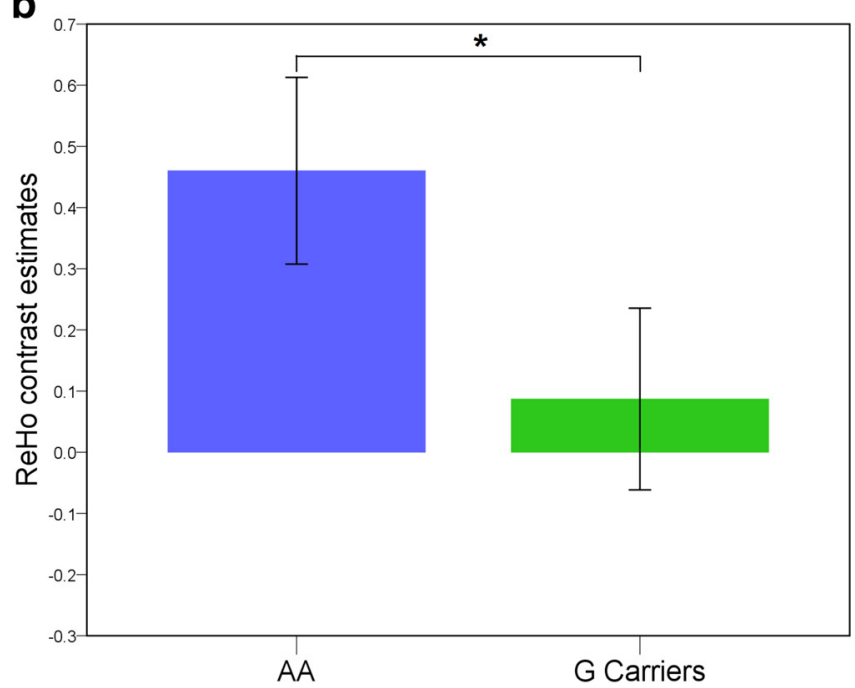

Figure 2. Difference in rs-fMRI values. For ALFFs (blue) and ReHo (green) between AA homozygotes and G carriers of the GAD2 rs2236418 in left pgACC (viewz $=-2$ ), with the pgACC voxel mask of $25 \%$ overlap (yellow), $50 \%$ overlap (red), and $75 \%$ overlap (pink) of subject's individual single-voxel location, dotted line represents transverse section. $\boldsymbol{a}$, Contrast estimates of ALFF at $x=-4$, $y=42, z=-2 . \boldsymbol{b}$, Contrast estimates of ReHo at $x=-2, y=42, z=-2 .{ }^{*} p<0.05,{ }^{\#} 0.1>p>0.05$. Error bars represent \pm 2 SEM of the contrast estimates.
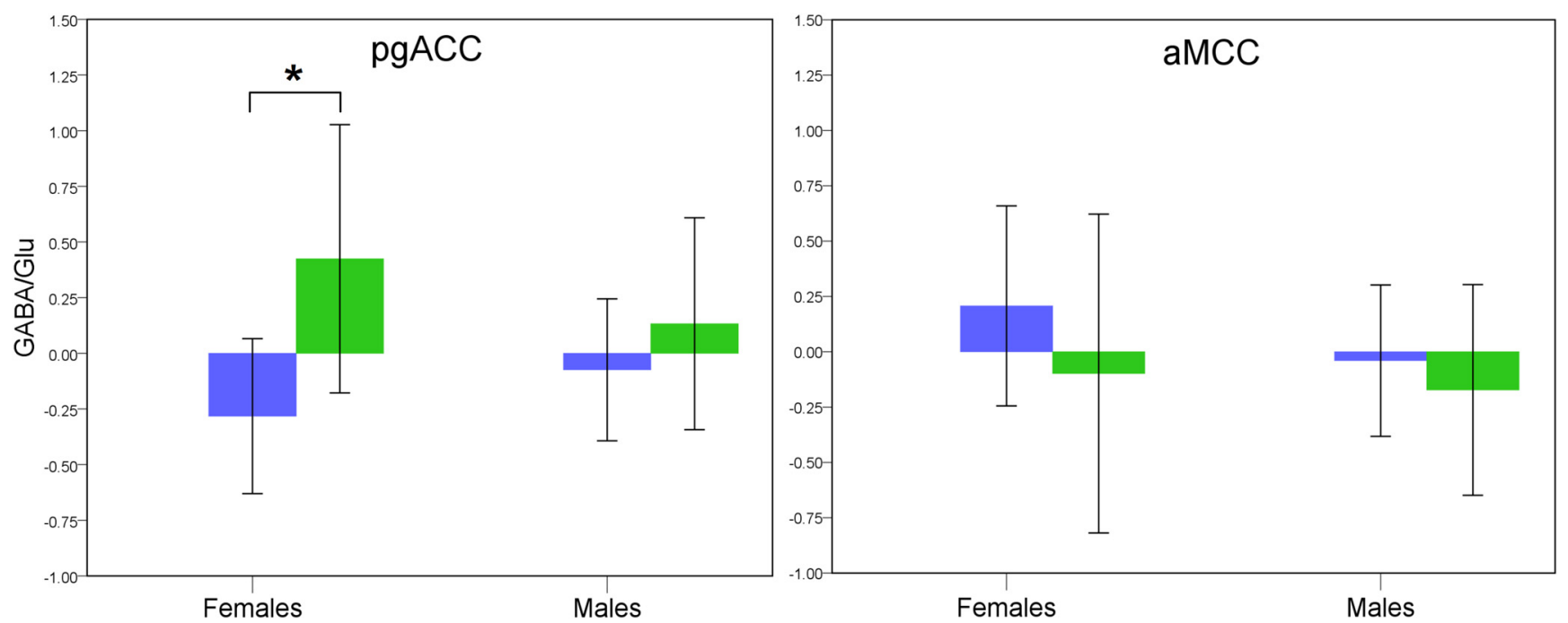

Figure 3. Differences in the $G A B A / G l u$ ratio. Posthoc results for the significant interaction of region by $G A D 2$ rs 2236418 by $\operatorname{sex}\left(F_{(1,63)}=8.66, p=0.005, \eta^{2}=0.12\right)$ for $G A B A / G l u$ ratio residuals, controlled for age. Depicted are GABA/Glu residuals in the pgACC (left) and aMCC (right) split by genotype (AA, blue; $G$ carriers, green) and sex: only in pgACC and only in females, $G$ carriers showed significantly increased GABA/Glu $\left(t_{(36)}=-2.19, p=0.035\right) .{ }^{*} p<0.05$. Error bars represent \pm 2 SEM. 
Table 4. Main analyses of the GABA/Glu levels within the ACC subregions for five investigated SNPs

\begin{tabular}{lll}
\hline Polymorphism & Effect & GABA/Glu \\
\hline GAD2 rs2236418 & Region $\times$ genotype & $F_{(1,63)}=7.53, p=0.008, \eta^{2}=0.11^{* *}$ \\
& Region $\times$ sex & $F_{(1,63)}=0.52, p=0.47, \eta^{2}=0.008$ \\
& Region $\times$ genotype $\times$ sex & $F_{(1,63)}=8.66, p=0.005, \eta^{2}=0.12^{* *}$ \\
GAD2 rs10508715 & Region $\times$ genotype & $F_{(1,61)}=0.25, p=0.62, \eta^{2}=0.004$ \\
& Region $\times$ sex & $F_{(1,61)}=0.29, p=0.60, \eta^{2}=0.005$ \\
& Region $\times$ genotype $\times$ sex & $F_{(1,61)}=0.81, p=0.37, \eta^{2}=0.013$ \\
GAD1 rs3791850 & Region $\times$ genotype & $F_{(1,60)}=0.01, p=0.93, \eta^{2}<0.001$ \\
& Region $\times$ sex & $F_{(1,60)}=0.48, p=0.49, \eta^{2}=0.008$ \\
GAD1 rs769390 & Region $\times$ genotype $\times$ sex & $F_{(1,60)}=0.82, p=0.37, \eta^{2}=0.013$ \\
& Region $\times$ genotype & $F_{(1,61)}=1.71, p=0.19, \eta^{2}=0.027$ \\
& Region $\times$ sex & $F_{(1,61)}=0.38, p=0.54, \eta^{2}=0.006$ \\
GLS rs13035504 & Region $\times$ genotype $\times$ sex & $F_{(1,61)}=0.15, p=0.69, \eta^{2}=0.002$ \\
& Region $\times$ genotype & $F_{(1,62)}=0.17, p=0.66, \eta^{2}=0.003$ \\
& Region $\times$ sex & $F_{(1,62)}=1.41, p=0.20, \eta^{2}=0.027$ \\
& Region $\times$ genotype $\times$ sex & $F_{(1,62)}=0.78, p=0.38, \eta^{2}=0.012$ \\
\hline
\end{tabular}

In the ANOVA model region was within-subject factor, genotype and sex between-subject factors, and age-nuisance covariate.

Bonferroni corrected threshold equal to ${ }^{* *} p<0.01$

Table 5. Post hoc analyses of the GABA/Glu levels within the ACC subregions

\begin{tabular}{lllll}
\hline Region & Sex & Genotype & Subjects, $n$ & Statistics \\
\hline aMCC & Males & AA & 27 & $U=211, p=0.458$ \\
& & G carriers & 18 & \\
& Females & AA & 24 & $U=82, p=0.564$ \\
& & G carriers & 8 & \\
pgACC & Males & AA & 30 & $U=317, p=0.615$ \\
& & G carriers & 23 & \\
& \multirow{2}{*}{ Females } & AA & 24 & $t=-2.19, \mathrm{df}=36, p=0.035^{*}$ \\
& & G carriers & 14 & \\
\hline
\end{tabular}

Student's $t$ test or Mann-Whitney's $U$ test (two-sided), were conducted to assess directionality for the significant ANOVA interactions, region by GAD2 rs2236418 by sex for the GABA/Glu ratios.

${ }^{*} p<0.05$.

in men $(b=0.059$, boot $95 \% \mathrm{CI}=[-0.334,1.451]$; Fig. 5$)$. A direct effect of genotype on harm avoidance was not significant in either sex (women: $b=4.926$, boot 95\% CI $=[-0.831,10.684]$; men: $b=1.726$, boot $95 \%$ CI $=[-3.026,6.478]$; Fig. 5). Other models did not show any significant effects. In short, the results are as follows: additive mediation model with pgACC GABA/Glu and ALFF (total indirect effects: $b=-0.641$, boot $95 \%$ CI $=$ $[-3.656,1.563]$; direct effect: $b=-0.903$, boot $95 \% \mathrm{CI}=$ $[-6.258,4.452])$, additive mediation model with pgACC GABA/ Glu and ReHo (total indirect effects: $b=0.114$, boot $95 \% \mathrm{CI}=$ $[-1.966,2.319]$; direct effect: $b=-1.658$, boot $95 \% \mathrm{CI}=$ $[-6.991,3.676])$, moderated mediation model with ALFF (moderated mediation index $=-1.291$, boot 95\% CI $=[-5.369$, 1.493]) and moderated mediation model with ReHo as mediator variable (moderated mediation index $=0.946$, boot $95 \% \mathrm{CI}=$ $[-1.612,4.937])$.

\section{Discussion}

The importance of the GABAergic system for anxiety endophenotypes and anxiety disorders, and their sex-biased occurrence is well established. In this study, by taking advantage of a polymorphism rs2236418 in the promoter region of GAD2, we demonstrate a role of inhibition/excitation balance in the pgACC and its association to anxiety-related traits, specifically in women.

We found reduced ALFF and ReHo of local intrinsic restingstate activity in the pgACC of G carriers (Fig. 2). Remarkably, GABA/Glu ratio differences were also detected, with $G$ carriers showing higher levels, indicative of a change in the inhibition/ excitation balance in the pgACC (Fig. 3; Table 4). Our results moreover showed metabolite (compared with GLS) and isoform specificity (compared with GAD1), as well as polymorphism specificity (Table 4). We speculate that polymorphism specificity may be due to transcription factor binding differences between two SNPs. The rs2236418 effects of the ratio were driven by the GABA/Cr ratio, however, with a smaller effect size (Table 6). Although Glu is a metabolic precursor of GABA, it is more abundant, so the presumed effect of the polymorphism on synthesis rates could have negligent effects on the total Glu concentration, while affecting GABA levels. Nevertheless, the functional consequence becomes prominent only when we consider the entire metabolic milieu, as seen for the GABA/Glu ratio.

Our data are in line with previous reports showing highest ratios of GABA/Glu in pregenual compared with mid and caudal ACC compartments mirrored by high densities of $\mathrm{GABA}_{\mathrm{B}}$ receptors (Dou et al., 2013). We used rs-fMRI considering the previously shown influence of local GABA concentrations on resting-state activity (Kapogiannis et al., 2013). The pgACC is a key region for automatic emotion regulation, and its hyperactivation has been linked to affective pathologies (Etkin et al., 2011), with increased ALFF reported in anxious depression (Liu et al., 2015) and ALFF and ReHo being positively associated with trait anxiety (Tian et al., 2016). Following the same regional pattern, lower GABA levels and elevated Glu levels have been found in social anxiety disorder and panic disorder (Phan et al., 2005; Long et al., 2013), indicating a shift of inhibition/excitation balance in various anxiety profiles. This regional behavioral congruity is also evident in healthy subjects as Hasler et al. (2010) described the connection between higher anxiety profiles and lower levels of GABA during anticipation of shock (Hasler et al., 2010). The interindividual variability in the molecular response to acute stress, measured via MRS, points to its importance for successful affect regulation, and possibly to genetic predispositions for anxiety phenotypes.

The relevance of GAD65 gene activity for anxiety and stress responsiveness has become evident in animal research (Müller et al., 2014). GAD65-deficient mice display higher anxiety levels and lower GABA in corticolimbic structures (Stork et al., 2000) and are more prone to develop post-traumatic stress disorderlike behavior upon fear stress (Bergado-Acosta et al., 2008; Sangha et al., 2009). Based on functionality and previous findings in animals, we did not expect a GAD65 effect in the aMCC, which is implicated in cognitive control and salience detection rather than emotion regulation (Menon and Uddin, 2010; Hoffstaedter et al., 2014). Furthermore, pgACC and aMCC differ in cell types and cortical layers (Vogt et al., 1995). Moreover, GAD65 and GAD67, although expressed in the vast majority of GABAergic neurons in the brain, differ in expression levels and regulation. Hence the GAD2 polymorphism is likely to act in a subregionspecific and cell-type-specific manner. In line, we could not observe an effect GAD1 rs769390 on GABA levels despite previously reported GABA differences in the larger midcingulate area (Marenco et al., 2010). Because the previous report of a SNPrelated sixfold change in the GAD65 expression levels refers to expression in a pancreatic cell line (Boutin et al., 2003), it needs to be further examined how the polymorphism affects gene expression in particular cell types in the pgACC.

Notably, genotype-dependent difference in the pgACC GABA/Glu ratio was most evident in women (Fig. 3; Table 4), suggesting that the rs 2236418 promoter polymorphism might affect the regulation of GAD65 expression levels, and consequentially levels of GABA, by sex hormones (Hudgens et al., 2009). 
Table 6. Exploratory analysis of GABA/Cr and Glu/Cr levels within the ACC subregions

\begin{tabular}{llll}
\hline Polymorphism & Effect & Glu/Cr & GABA/Cr \\
\hline GAD1 rs2236418 & Region $\times$ genotype & $F_{(1,69)}=0.51, p=0.48, \eta^{2}=0.007$ & $F_{(1,63)}=3.57, p=0.063, \eta^{2}=0.054^{\#}$ \\
& Region $\times$ genotype $\times$ sex & $F_{(1,69)}=0.002, p=0.97, \eta^{2}<0.001$ & $F_{(1,63)}=4.92, p=0.03, \eta^{2}=0.072^{*}$ \\
GAD1 rs10508715 & Region $\times$ genotype & $F_{(1,67)}=2.50, p=0.12, \eta^{2}=0.036$ & $F_{(1,61)}=0.001, p=0.98, \eta^{2}<0.001$ \\
& Region $\times$ genotype $\times$ sex & $F_{(1,67)}=1.55, p=0.22, \eta^{2}=0.023$ & $F_{(1,61)}=0.09, p=0.76, \eta^{2}=0.002$ \\
GAD2 rs3791850 & Region $\times$ genotype & $F_{(1,66)}=0.44, p=0.51, \eta^{2}=0.007$ & $F_{(1,60)}=0.27, p=0.61, \eta^{2}=0.004$ \\
& Region $\times$ genotype $\times$ sex & $F_{(1,66)}=0.99, p=0.32, \eta^{2}=0.015$ & $F_{(1,60)}=0.20, p=0.66, \eta^{2}=0.003$ \\
GAD2 rs769390 & Region $\times$ genotype & $F_{(1,67)}=0.009, p=0.93, \eta^{2}<0.001$ & $F_{(1,61)}=2.06, p=0.16, \eta^{2}=0.033$ \\
& Region $\times$ genotype $\times$ sex & $F_{(1,67)}=0.84, p=0.36, \eta^{2}=0.012$ & $F_{(1,61)}=0.57, p=0.45, \eta^{2}=0.009$ \\
GLS rs13035504 & Region $\times$ genotype & $F_{(1,68)}=2.29, p=0.14, \eta^{2}=0.033$ & $F_{(1,62)}=0.89, p=0.35, \eta^{2}=0.014$ \\
& Region $\times$ genotype $\times$ sex & $F_{(1,68)}=4.18, p=0.016, \eta^{2}=0.082^{*}$ & $F_{(1,62)}=3.56, p=0.064, \eta^{2}=0.054^{\#}$ \\
\hline
\end{tabular}

In the ANOVA model region was within-subject factor, genotype and sex between-subject factors, and age-nuisance covariate, statistical threshold was set at $p<0.05$.

${ }^{*} p<0.05 ;{ }^{*} 0.1>p>0.05$.

This is in line with previously reported sex and hormonal effects on the GABAergic system (Seney et al., 2013; Barth et al., 2015). It is appealing to consider that the interaction between sex hormones and the GABAergic system might contribute to the higher prevalence of anxiety disorders in women. A previous study linking SNPs in the GAD1 gene, coding for the second GAD isoform, GAD67, to panic disorder only in women (Weber et al., 2012), further supports this idea. It is thus of critical interest to explore sex-related variance in both preclinical and human research (Blanchard et al., 1995; Zakiniaeiz et al., 2016), also in terms of genetic variation.

Personality associations of the GABA/ Glu ratio with harm avoidance were also present only in women (Fig. 4). Harm avoidance is considered a personality dimension tightly coupled with anxiety proneness (Cloninger et al., 1994) and in a healthy population reflects an endophenotype that might convert to disease phenotypes in patient populations (Zohar et al., 2003). In the light of the negative association of harm avoidance and GABA/Glu ratios, we suggest that at least in women, increased inhibition/excitation balance in the pgACC could denote protective mechanisms toward increased anxiety.

The relationship of gene and behavior in our study is best accounted for within the interaction of sex and metabolite mediators; in women the effect of the GAD2 rs2236418 variation on harm avoidance became evident only when GABA/Glu levels were considered (Fig. 5). This was specific for the metabolites as rs-fMRI estimates did not show any significant mediation. In the mediation model, it was delineated that female $G$ carriers potentially have higher harm avoidance scores within the same inhibition/excitation levels. This finding suggests a complex interplay between genes encoding components
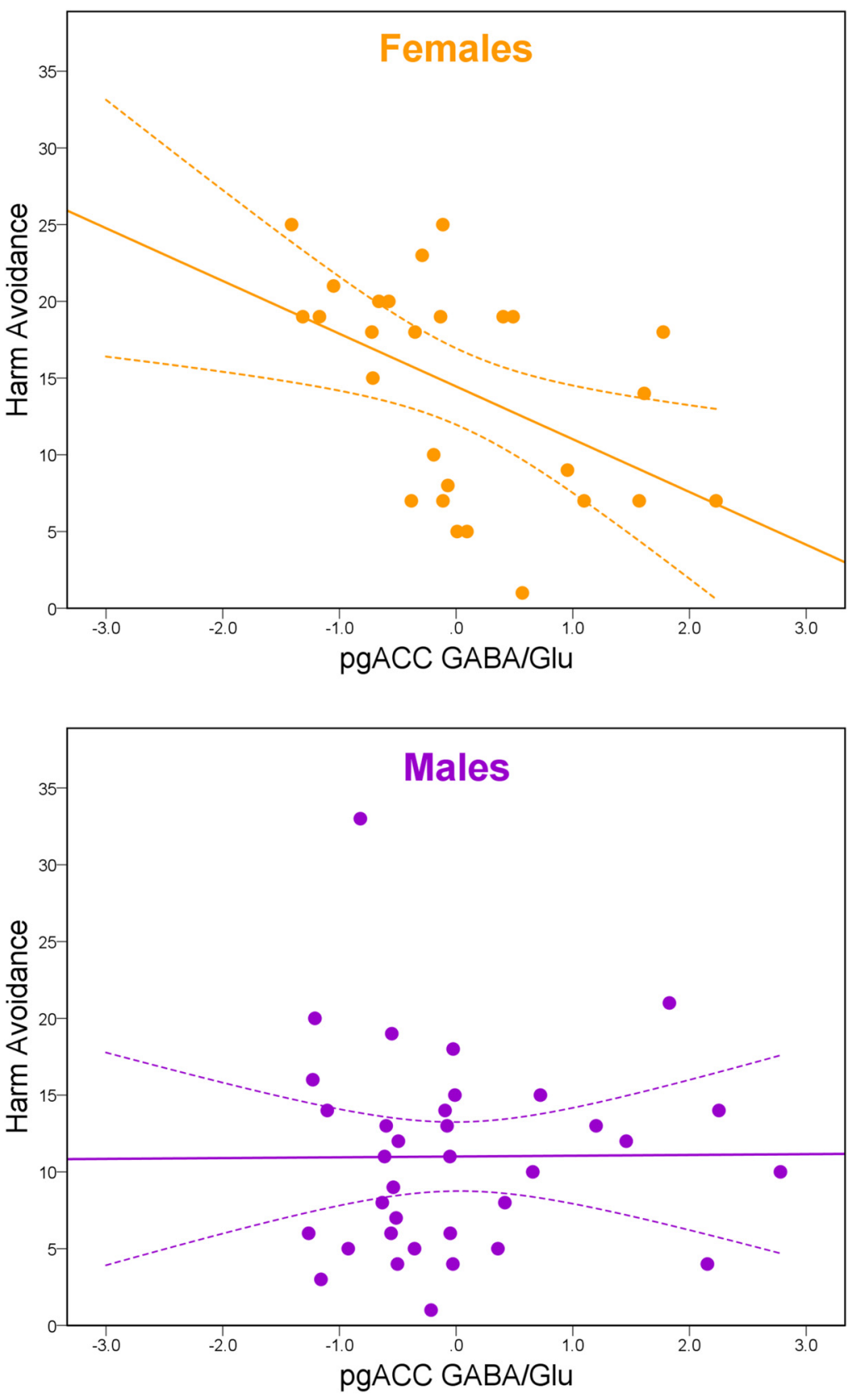

Figure 4. Harm avoidance and GABA/Glu ratio in the pgACC. Correlation slopes of harm avoidance and pgACC GABA/Glu residuals differed significantly $(p=0.014)$ between women $\left(\rho_{(24)}=-0.549, p=0.004\right.$; orange) and men $\left(\rho_{(32)}=0.048, p=\right.$ 0.79 ; purple). Cls depict $95 \%$ of the mean. 


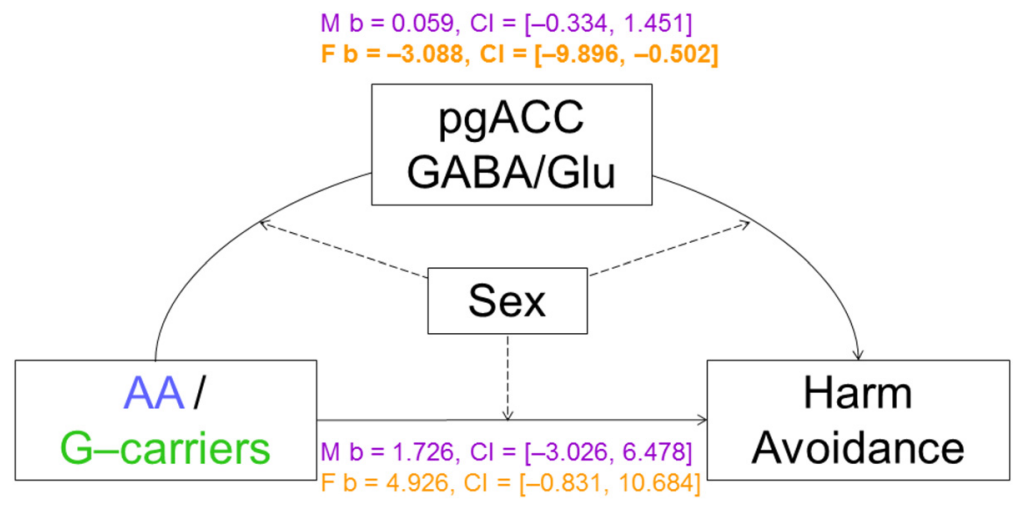

Figure 5. Mediation model moderated by sex. Index $=-3.147$, bootstrapped $95 \% \mathrm{Cl}=(-9.929,-0.478)$; in both sexes the direct effect of GAD65 genotype on harm avoidance was not significant. However for the indirect effect, the GABA/Glu ratio (curved arrow), in the pgACC significantly mediated the relationship between GAD65 and harm avoidance in women $(b=$ -3.088 , boot $95 \% \mathrm{Cl}=[-9.896,-0.502]$; bold), but not in men. $M$, Males (purple); $F$, females (orange); $b$, effect.

of the GABAergic system and sex hormones in anxiety endophenotypes. The functional consequence of genetic polymorphisms must be viewed in terms of their plasticity potential which can be either protective or disadvantageous depending on the environment (Meyer-Lindenberg and Weinberger, 2006). Consequently, female $\mathrm{G}$ carriers might be conservative for anxiety phenotypes in healthy young subjects. This might not hold true for other situations such as during childhood stress or trauma and it will be interesting to determine how GAD65 genotype affects clinically relevant changes in affect regulation, including trauma resilience or vulnerability.

This multimodal study has several constraints that need to be taken into account. Due to quality exclusion criteria and incomplete measurements some genotype/sex subgroups have modest number of participants. However, it should also be noted that a previous meta-analysis of the well known COMT Val108/158Met polymorphism has shown that neuroimaging phenotypes are more strongly associated with gene variants compared with behavioral or disease phenotypes (Mier et al., 2010). We argued that this was most likely due to the neural activity and the resulting BOLD response being more proximal to the cellular effects of genetic variations. Analogously, it should be noted that the metabolic ratio may associate even more closely with the genotype difference, whereas, in a healthy population, baseline BOLD might be compensated by other factors such as vascular responsiveness. The high-field $7 \mathrm{~T}$ allowed us to analyze high-resolution data ( $2 \mathrm{~mm}$ acquisition voxel), as well as implement specific MRS sequence to obtain both GABA and Glu (Dou et al., 2013) at high quality in multiple regions, yielding neurochemical measures that should be sufficiently close to the immediate biological effects of the genotype. This limited us to scan at a single site in Magdeburg, which offered the requested technical conditions, instead of using protocols which would allow replication or pooling from other centers. We nevertheless recognize that study warrants future replication, preferably with sufficient power to detect group differences at the level of behavior. Given the results of our study, one could decide to return to lower field strengths and focus on one region or specifically on GABA. Moreover, we did not control for the menstrual cycle in our female participants which might have brought an additional dimension. Functional associations between genes, metabolites and harm avoidance were only present in women implying differential modulation of gene effect either through transcription activity, or through hormones (Seney et al., 2013). Additionally, it was reported that menstrual cycle can influence MRS (Epperson et al., 2002; Batra et al., 2008). Therefore, we cannot exclude the effect of cycle on GABA/Glu ratio, but one can expect similar distribution of menstrual phases between genotypes in randomly picked sample from a healthy young population.

In conclusion, our findings suggest that a GAD2 genotype-by-sex interaction shapes GABAergic inhibition in the pgACC, and its control of anxietyrelated traits. Our results provide new insight into the complex and regionspecific regulation of GABAergic inhibition and the development of transitional phenotype particularly in women, which is highly relevant for the development of affective pathologies.

\section{References}

Barth C, Villringer A, Sacher J (2015) Sex hormones affect neurotransmitters and shape the adult female brain during hormonal transition periods. Front Neurosci 9:37. CrossRef Medline

Batra NA, Seres-Mailo J, Hanstock C, Seres P, Khudabux J, Bellavance F, Baker G, Allen P, Tibbo P, Hui E, Le Melledo JM (2008) Proton magnetic resonance spectroscopy measurement of brain glutamate levels in premenstrual dysphoric disorder. Biol Psychiatry 63:1178-1184. CrossRef Medline

Bergado-Acosta JR, Sangha S, Narayanan RT, Obata K, Pape HC, Stork O (2008) Critical role of the 65-kDa isoform of glutamic acid decarboxylase in consolidation and generalization of Pavlovian fear memory. Learn Mem 15:163-171. CrossRef Medline

Biswal BB, Mennes M, Zuo XN, Gohel S, Kelly C, Smith SM, Beckmann CF, Adelstein JS, Buckner RL, Colcombe S, Dogonowski AM, Ernst M, Fair D, Hampson M, Hoptman MJ, Hyde JS, Kiviniemi VJ, Kötter R, Li SJ, Lin $\mathrm{CP}$, et al. (2010) Toward discovery science of human brain function. Proc Natl Acad Sci U S A 107:4734-4739. CrossRef Medline

Blanchard DC, Griebel G, Blanchard RJ (1995) Gender bias in the preclinical psychopharmacology of anxiety: male models for (predominantly) female disorders. J Psychopharmacol 9:79-82. CrossRef Medline

Boutin P, Dina C, Vasseur F, Dubois S, Corset L, Séron K, Bekris L, Cabellon J, Neve B, Vasseur-Delannoy V, Chikri M, Charles MA, Clement K, Lernmark A, Froguel P (2003) GAD2 on chromosome 10p12 is a candidate gene for human obesity. PLoS Biol 1:E68. CrossRef Medline

Bush G, Luu P, Posner MI (2000) Cognitive and emotional influences in anterior cingulate cortex. Trends Cogn Sci 4:215-222. CrossRef Medline

Chao-Gan Y, Yu-Feng Z (2010) DPARSF: a MATLAB toolbox for "pipeline" data analysis of resting-state fMRI. Front Syst Neurosci 4:13. CrossRef Medline

Cline H (2005) Synaptogenesis: a balancing act. Curr Biol 15:R203-205. CrossRef Medline

Cloninger CR (1987) A systematic method for clinical description and classification of personality variants. Arch Gen Psychiatry 44:573-588. CrossRef Medline

Cloninger CR, Przybeck TR, Svrakic DM (1994) The temperament and character inventory (TCI): a guide to its development and use. St. Louis: Center for Psychobiology of Personality, Washington University.

Davis AM, Ward SC, Selmanoff M, Herbison AE, McCarthy MM (1999) Developmental sex differences in amino acid neurotransmitter levels in hypothalamic and limbic areas of rat brain. Neuroscience 90:1471-1482. CrossRef Medline

De Fruyt F, Van De Wiele L, Van Heeringen C (2000) Cloninger's psychobiological model of temperament and character and the five-factor model of personality. Pers Individ Dif 29:441-452. CrossRef

Donner NC, Lowry CA (2013) Sex differences in anxiety and emotional behavior. Pflugers Arch 465:601-626. CrossRef Medline

Dörfel D, Lamke JP, Hummel F, Wagner U, Erk S, Walter H (2014) Common and differential neural networks of emotion regulation by detach- 
ment, reinterpretation, distraction, and expressive suppression: a comparative fMRI investigation. Neuroimage 101:298-309. CrossRef Medline

Dou W, Palomero-Gallagher N, van Tol MJ, Kaufmann J, Zhong K, Bernstein HG, Heinze HJ, Speck O, Walter M (2013) Systematic regional variations of GABA, glutamine, and glutamate concentrations follow receptor fingerprints of human cingulate cortex. J Neurosci 33:12698-12704. CrossRef Medline

Epperson CN, Haga K, Mason GF, Sellers E, Gueorguieva R, Zhang W, Weiss E, Rothman DL, Krystal JH (2002) Cortical $\gamma$-aminobutyric acid levels across the menstrual cycle in healthy women and those with premenstrual dysphoric disorder. Arch Gen Psychiatry 59:851-858. CrossRef Medline

Esclapez M, Tillakaratne NJ, Kaufman DL, Tobin AJ, Houser CR (1994) Comparative localization of two forms of glutamic acid decarboxylase and their mRNAs in rat brain supports the concept of functional differences between the forms. J Neurosci 14:1834-1855. CrossRef Medline

Etkin A, Egner T, Kalisch R (2011) Emotional processing in anterior cingulate and medial prefrontal. Trends Cogn Sci 15:85-93. CrossRef Medline

Giustino TF, Maren S (2015) The role of the medial prefrontal cortex in the conditioning and extinction of fear. Front Behav Neurosci 9:298. CrossRef Medline

Goddard AW (2016) Cortical and subcortical gamma amino acid butyric acid deficits in anxiety and stress disorders: clinical implications. World J Psychiatry 6:43-53. CrossRef Medline

Hasler G, van der Veen JW, Grillon C, Drevets WC, Shen J (2010) Effect of acute psychological stress on prefrontal GABA concentration determined by proton magnetic resonance spectroscopy. Am J Psychiatry 167:12261231. CrossRef Medline

Hettema JM, An SS, Neale MC, Bukszar J, van den Oord EJ, Kendler KS, Chen X (2006) Association between glutamic acid decarboxylase genes and anxiety disorders, major depression, and neuroticism. Mol Psychiatry 11:752-762. CrossRef Medline

Hoffstaedter F, Grefkes C, Caspers S, Roski C, Palomero-Gallagher N, Laird AR, Fox PT, Eickhoff SB (2014) The role of anterior midcingulate cortex in cognitive motor control: evidence from functional connectivity analyses. Hum Brain Mapp 35:2741-2753. CrossRef Medline

Hudgens ED, Ji L, Carpenter CD, Petersen SL (2009) The gad2 promoter is a transcriptional target of estrogen receptor (ER) $\alpha$ and ER $\beta$ : a unifying hypothesis to explain diverse effects of estradiol. J Neurosci 29:87908797. CrossRef Medline

Ikeda T, Makino Y, Yamada MK (2015) $17 \alpha$-Estradiol is generated locally in the male rat brain and can regulate GAD65 expression and anxiety. Neuropharmacology 90:9-14. CrossRef Medline

Jenkinson M, Bannister P, Brady M, Smith S (2002) Improved optimization for the robust and accurate linear registration and motion correction of brain images. Neuroimage 17:825-841. CrossRef Medline

Josefsson K, Jokela M, Cloninger CR, Hintsanen M, Salo J, Hintsa T, PulkkiRåback L, Keltikangas-Järvinen L (2013) Maturity and change in personality: developmental trends of temperament and character in adulthood. Dev Psychopathol 25:713-727. CrossRef Medline

Kapogiannis D, Reiter DA, Willette AA, Mattson MP (2013) Posteromedial cortex glutamate and GABA predict intrinsic functional connectivity of the default mode network. Neuroimage 64:112-119. CrossRef Medline

Li M, Demenescu LR, Colic L, Metzger CD, Heinze HJ, Steiner J, Speck O, Fejtova A, Salvadore G, Walter M (2017) Temporal dynamics of antidepressant ketamine effects on glutamine cycling follow regional fingerprints of AMPA and NMDA receptor densities. Neuropsychopharmacology 42:1201-1209. CrossRef Medline

Liu CH, Ma X, Song LP, Fan J, Wang WD, Lv XY, Zhang Y, Li F, Wang L, Wang CY (2015) Abnormal spontaneous neural activity in the anterior insular and anterior cingulate cortices in anxious depression. Behav Brain Res 281:339-347. CrossRef Medline

Long Z, Medlock C, Dzemidzic M, Shin YW, Goddard AW, Dydak U (2013) Progress in neuro-psychopharmacology and biological psychiatry decreased GABA levels in anterior cingulate cortex/medial prefrontal cortex in panic disorder. Prog Neuropsychopharmacol Biol Psychiatry 44:131135. CrossRef Medline

Marenco S, Savostyanova AA, van der Veen JW, Geramita M, Stern A, Barnett AS, Kolachana B, Radulescu E, Zhang F, Callicott JH, Straub RE, Shen J, Weinberger DR (2010) Genetic modulation of GABA levels in the anterior cingulate cortex by GAD1 and COMT. Neuropsychopharmacology 35:1708-1717. CrossRef Medline
Mathews A, MacLeod C (2005) Cognitive vulnerability to emotional disorders. Annu Rev Clin Psychol 1:167-195. CrossRef Medline

McCarthy MM, Kaufman LC, Brooks PJ, Pfaff DW, Schwartz-Giblin S (1995) Estrogen modulation of mRNA levels for the two forms of glutamic acid decarboxylase (GAD) in female rat brain. J Comp Neurol 360:685-697. CrossRef Medline

McLean CP, Asnaani A, Litz BT, Hofmann SG (2011) Gender differences in anxiety disorders: prevalence, course of illness, comorbidity and burden of illness. J Psychiatr Res 45:1027-1035. CrossRef Medline

Menon V, Uddin LQ (2010) Saliency, switching, attention and control: a network model of insula function. Brain Struct Funct 214:655-667. CrossRef Medline

Meyer-Lindenberg A, Weinberger DR (2006) Intermediate phenotypes and genetic mechanisms of psychiatric disorders. Nat Rev Neurosci 7:818827. CrossRef Medline

Mier D, Kirsch P, Meyer-Lindenberg A (2010) Neural substrates of pleiotropic action of genetic variation in COMT: a meta-analysis. Mol Psychiatry 15:918-927. CrossRef Medline

Miettunen J, Kantojärvi L, Veijola J, Järvelin MR, Joukamaa M (2006) International comparison of Cloninger's temperament dimensions. Pers Individ Dif 41:1515-1526. CrossRef

Müller I, Obata K, Richter-Levin G, Stork O (2014) GAD65 haplodeficiency conveys resilience in animal models of stress-induced psychopathology. Front Behav Neurosci 8:265. CrossRef Medline

Northoff G, Walter M, Schulte RF, Beck J, Dydak U, Henning A, Boeker H, Grimm S, Boesiger P (2007) GABA concentrations in the human anterior cingulate cortex predict negative BOLD responses in fMRI. Nat Neurosci 10:1515-1517. CrossRef Medline

Nuss P (2015) Anxiety disorders and GABA neurotransmission: a disturbance of modulation. Neuropsychiatr Dis Treat 11:165-175. CrossRef Medline

Oldfield RC (1971) The assessment and analysis of handedness: the Edinburgh inventory. Neuropsychologia 9:97-113. CrossRef Medline

Palomero-Gallagher N, Vogt BA, Schleicher A, Mayberg HS, Zilles K (2009) Receptor architecture of human cingulate cortex: evaluation of the fourregion neurobiological model. Hum Brain Mapp 30:2336-2355. CrossRef Medline

Patel AB, de Graaf RA, Martin DL, Battaglioli G, Behar KL (2006) Evidence that GAD65 mediates increased GABA synthesis during intense neuronal activity in vivo. J Neurochem 97:385-396. CrossRef Medline

Phan KL, Fitzgerald DA, Cortese BM, Seraji-Bozorgzad N, Tancer ME, Moore GJ (2005) Anterior cingulate neurochemistry in social anxiety disorder: $1 \mathrm{H}-\mathrm{MRS}$ at 4 Tesla. Neuroreport 16:183-186. CrossRef Medline

Preacher KJ, Hayes AF (2004) SPSS and SAS procedures for estimating indirect effects in simple mediation models. Behav Res Methods Instrum Comput 36:717-731. CrossRef Medline

Provencher SW (2001) Automatic quantitation of localized in vivo ${ }^{1} \mathrm{H}$ spectra with LCModel. NMR Biomed 14:260-264. CrossRef Medline

Richter J, Eisemann M, Richter G (2000) Zur deutschsprachigen version des temperament: und charakterinventars. Z Klin Psychol Psychother 29: 117-126. CrossRef

Sangha S, Narayanan RT, Bergado-Acosta JR, Stork O, Seidenbecher T, Pape HC (2009) Deficiency of the $65 \mathrm{kDa}$ isoform of glutamic acid decarboxylase impairs extinction of cued but not contextual fear memory. J Neurosci 29:15713-15720. CrossRef Medline

Seney ML, Chang LC, Oh H, Wang X, Tseng GC, Lewis DA, Sibille E (2013) The role of genetic sex in affect regulation and expression of GABArelated genes across species. Front Psychiatry 4:104. CrossRef Medline

Sheehan DV, Lecrubier Y, Sheehan KH, Amorim P, Janavs J, Weiller E, Hergueta T, Baker R, Dunbar GC (1998) The mini-international neuropsychiatric interview (M.I.N.I.): the development and validation of a structured diagnostic psychiatric interview for DSM-IV and ICD-10. J Clin Psychiatry 59:22-33;quiz 34-57. Medline

Soghomonian JJ, Martin DL (1998) Two isoforms of glutamate decarboxylase: why? Trends Pharmacol Sci 19:500-505. CrossRef Medline

Speck O, Stadler J, Zaitsev M (2008) High resolution single-shot EPI at 7T. MAGMA 21:73-86. CrossRef Medline

Stallings MC, Hewitt JK, Cloninger CR, Heath AC, Eaves LJ (1996) Genetic and environmental structure of the tridimensional personality questionnaire: three or four temperament dimensions? J Pers Soc Psychol 70:127140. CrossRef Medline

Stork O, Ji FY, Kaneko K, Stork S, Yoshinobu Y, Moriya T, Shibata S, Obata K 
(2000) Postnatal development of a GABA deficit and disturbance of neural functions in mice lacking GAD65. Brain Res 865:45-58. CrossRef Medline

Straube T, Schmidt S, Weiss T, Mentzel HJ, Miltner WH (2009) Dynamic activation of the anterior cingulate cortex during anticipatory anxiety. Neuroimage 44:975-981. CrossRef Medline

Tian X, Wei D, Du X, Wang K, Yang J, Liu W, Meng J, Liu H, Liu G, Qiu J (2016) Neuroimage assessment of trait anxiety and prediction of changes in state anxiety using functional brain imaging: a test-retest study. Neuroimage 133:408-416. CrossRef Medline

Unschuld PG, Ising M, Specht M, Erhardt A, Ripke S, Heck A, Kloiber S, Straub V, Brueckl T, Müller-Myhsok B, Holsboer F, Binder EB (2009) Polymorphisms in the GAD2 gene-region are associated with susceptibility for unipolar depression and with a risk factor for anxiety disorders. Am J Med Genet B Neuropsychiatr Genet 150B:1100-1109. CrossRef Medline

Vogt BA, Nimchinsky EA, Vogt LJ, Hof PR (1995) Human cingulate cortex: surface features, flat maps, and cytoarchitecture. J Comp Neurol 359: 490-506. CrossRef Medline

Weber H, Scholz CJ, Domschke K, Baumann C, Klauke B, Jacob CP, Maier W, Fritze J, Bandelow B, Zwanzger PM, Lang T, Fehm L, Ströhle A, Hamm A, Gerlach AL, Alpers GW, Kircher T, Wittchen HU, Arolt V, Pauli P, et al. (2012) Gender differences in associations of glutamate decarboxylase 1 gene (GAD1) variants with panic disorder. PLoS One 7:e37651. CrossRef Medline

Yin H, Pantazatos SP, Galfalvy H, Huang YY, Rosoklija GB, Dwork AJ, Burke A, Arango V, Oquendo MA, Mann JJ (2016) A pilot integrative genomics study of GABA and glutamate neurotransmitter systems in suicide, suicidal behavior, and major depressive disorder. Am J Med Genet B Neuropsychiatr Genet 171B:414-426. CrossRef Medline

Yu C, Zhou Y, Liu Y, Jiang T, Dong H, Zhang Y, Walter M (2011) Functional segregation of the human cingulate cortex is confirmed by functional connectivity based neuroanatomical parcellation. Neuroimage 54:25712581. CrossRef Medline

Zakiniaeiz Y, Cosgrove KP, Potenza MN, Mazure CM (2016) Balance of the sexes: addressing sex differences in preclinical research. Yale J Biol Med 89:255-259. Medline

Zang Y, Jiang T, Lu Y, He Y, Tian L (2004) Regional homogeneity approach to fMRI data analysis. Neuroimage 22:394-400. CrossRef Medline

Zohar AH, Dina C, Rosolio N, Osher Y, Gritsenko I, Bachner-Melman R, Benjamin J, Belmaker RH, Ebstein RP (2003) Tridimensional personality questionnaire trait of harm avoidance (anxiety proneness) is linked to a locus on chromosome 8p21. Am J Med Genet B Neuropsychiatr Genet 117B:66-69. CrossRef Medline

Zuo XN, Di Martino A, Kelly C, Shehzad ZE, Gee DG, Klein DF, Castellanos FX, Biswal BB, Milham MP (2010) Neuroimage the oscillating brain: complex and reliable. Neuroimage 49:1432-1445. CrossRef Medline 